\title{
Distribution of simple phenols, phenolic acids and flavonoids in Turkish monovarietal extra virgin olive oils for two harvest years
}

\author{
Derya Ocakoglu, Figen Tokatli *, Banu Ozen, Figen Korel \\ Izmir Institute of Technology, Department of Food Engineering, Gulbahce Campus, 35430 Urla-Izmir, Turkey
}

\section{A R T I C L E I N F O}

\section{Article history:}

Received 4 April 2008

Received in revised form 30 June 2008

Accepted 19 July 2008

\section{Keywords:}

Olive oil

Phenolics

Cultivar

Harvest year

\begin{abstract}
A B S T R A C T
Monovarietal extra virgin olive oils extracted from six dominant and economically important Turkish olive cultivars (memecik, erkence, domat, nizip-yaglik, gemlik, ayvalik) were examined for their simple phenolics, phenolic acids and flavonoid compounds over 2005 and 2006 harvest years. Total phenol contents, oxidative stabilities and chromatic ordinates as colour parameters were also measured. The most typical phenolic compounds that were identified in both years are hydroxytyrosol, tyrosol, vanillic acid, p-coumaric acid, cinnamic acid, luteolin, and apigenin. Multivariate data were analysed by principal component and partial least square-discriminant analyses. It was observed that phenolic profiles of olive oils depended highly on harvest season. In addition, oils of different olive cultivars have different distribution of phenols. No significant correlation was observed between oxidative stability and phenolic compounds. Increase in peroxide value over an accelerated oxidation period of 11 days showed weak correlations with total phenol content, vanillin, syringic acid and colour parameter $a^{*}$, as $0.56,0.55,-0.42$, and 0.51 , respectively, in terms of correlation coefficient $r$.
\end{abstract}

(ㄷ) 2008 Elsevier Ltd. All rights reserved.

\section{Introduction}

Phenolic compositions of food materials have been the scope of many studies lately due to their antioxidant and antimicrobial effects. The olive and olive oil, in this matter, are being examined for their phenolic compounds since they are the main ingredients of Mediterranean diet, which has been proven for its positive health effects (Tuck, Hayball, \& Stupans, 2002; Visioli, Poli, \& Galli, 2002).

The importance of virgin olive oil (VOO) is related to its high levels of monounsaturated fatty acids (mainly oleic acid) and to the presence of minor components including aliphatic and triterpenic alcohols, sterols, hydrocarbons, volatile compounds, and several antioxidants. The fundamental antioxidants of VOO are carotenoids and phenolic compounds, which have both lipophilic and hydrophilic properties. Tocopherols are known as lipophilics, while phenolic alcohols and acids, hydroxy-isochromans, flavonoids, secoiridoids, and lignans constitute the hydrophilic compounds. Phenolic acids with the basic chemical structure of $C_{6}-C_{1}$ (benzoic acids) and $\mathrm{C}_{6}-\mathrm{C}_{3}$ (cinnamic acid) are found in olive fruit. The compounds, such as caffeic, vanillic, syringic, p-coumaric, $o$-coumaric, protocatechuic, sinapic and $p$-hydroxybenzoic acid are the first group of phenols observed in VOO. Hydroxytyrosol

\footnotetext{
* Corresponding author. Tel.: +90 232750 6295; fax: +90 2327506196.

E-mail addresses: figentokatli@iyte.edu.tr, figentokatli@gmail.com (F. Tokatli).
}

(3,4-dihydroxyphenyl-ethanol) and tyrosol ( $p$-hydroxyphenyl-ethanol) are the most abundant phenolic alcohols in olives. The secoiridoids (oleuropein aglycon, demethyloleuropein, ligstroside aglycon) and the lignans (1-acetoxypinoresinol, pinoresinol) have also been isolated and characterised. Luteolin and apigenin are the flavonoid compounds of olive oil (Bendini et al., 2007).

Phenolic compounds make important contributions to the nutritional properties, sensory characteristics, and the shelf life of olive oil. Those derived from the hydrolysis of oleuropein contribute to the intensity of the bitterness of virgin olive oil, and especially hydroxytyrosol, tyrosol, caffeic acid, coumaric acids, and p-hydroxybenzoic acid influence the sensory characteristics of olive oil (Kiritsakis, 1998). Phenolic compounds play an important role in human health because of their anti-inflammatory, antiallergic, antimicrobial, anticarcinogenic, and antiviral activities (Medina, Brenes, Romero, Garcia, \& De Castro, 2007). They prevent lipid peroxidation and oxidative modification of low density lipoprotein (LDL) by means of their antioxidant activities (Servili et al., 2004).

The concentration and composition of phenolic compounds in VOO is strongly affected by many agronomical and technological factors, such as olive cultivar (Tura et al., 2007), the place of cultivation (Vinha et al., 2005), the climate, degree of maturation (Kalua, Allen, Bedgood, Bishop, \& Prenzler, 2005), crop season (Gomez-Alonso, Salvador, \& Fregapane, 2002), irrigation (Tovar, Motilva, \& Romero, 2001) and the production process (Ranalli, Contento, Schiavone, \& Simone, 2001). 
Many studies have been reported on the classification of olive oils according to their cultivar or geographical origin by means of statistical analysis applied to fatty acids and triacylglycerols (Stefanoudaki, Kotsifaki, \& Koutsaftakis, 1997), sterol compositions (Alves, Cunha, Amaral, Pereira, \& Oliveira, 2005), sensory attributes (Haddada et al., 2007), and also minor components (Cerretani et al., 2006).

Best of our knowledge, little has been published about olive oils produced in Turkey, which is in the fifth place in the olive oil production (5\%) in the world and contributes $11.3 \%$ of the world export (International Olive Council, 2008). The aim of this study was to evaluate the phenolic profiles of Turkish extra VOOs obtained from six olive varieties, which were chosen among the most dominant and economically important types, for two harvest years. Quantitative parameters including peroxide value, total phenol content, colour, and individual phenolic compounds of oil samples were determined, and the influence of the cultivar and harvest year on these parameters was studied. The classification of olive oil samples according to their phenolic profiles was performed by principal component analysis (PCA) and partial least squares-discriminant analysis (PLS-DA).

\section{Materials and methods}

\subsection{Olive oil samples}

Olive varieties used in this study are erkence $(E)$, memecik (M), domat (D), nizip-yaglik (N), gemlik (G) and ayvalik (A). Ayvalik variety is also known as edremit-yaglik. Nizip is a variety cultivated in the south-east part of the country and has very high oil productivity. Other cultivars are indigenous to the west cost. All the olive varieties are used mainly in oil production except domat, which is an important variety in table olive production. The olives were obtained from a nursery in Izmir, a city in the Aegean cost of Turkey (Research Institute of Olive, Izmir, Turkey). Gemlik \& ayvalik varieties (GE \& AE) were also obtained from an olive grove, which is about $150 \mathrm{~km}$ north of Izmir (Edremit Olive Nursery, Balikesir, Turkey) in order to study the possible geographical differences among the same cultivars. Olive fruit samples were hand-picked randomly from olive trees at the beginning of November in 2005 and 2006 harvest years, at the same maturity level. Only healthy fruits, without any kind of infection or physical damage, were used. Olive fruits of each variety were randomly distributed in $5 \mathrm{~kg}$ batches for the extraction processes. Olive oils were produced in a $5 \mathrm{~kg}$ capacity laboratory scale olive mill (Spremoliva, Italy) in the Department of Food Engineering at Izmir Institute of Technology. Olive oil samples were stored at $9{ }^{\circ} \mathrm{C}$ in dark bottles and the headspaces were replaced by nitrogen prior to analyses. The extraction of each variety was replicated minimum twice, and maximum five times in both years. The chemical analyses were performed after the extraction process in each particular year. All oil samples are extra virgin olive oil samples with respect to European Commission regulations EEC 1991, since \% free fatty acid contents are less than $1.0 \%$ (data not given). The numbers beside each letter designated for oil samples represent the extraction batch and 05 and 06 represent the harvest years. 48 samples were analysed in total.

\subsection{Chemicals}

The following standards were used in the quantification of phenolic substances in olive oil samples: Gallic acid, hydroxytyrosol, 4-hydroxybenzoic acid, tyrosol, chlorogenic acid, 2,3 dihydroxybenzoic acid, 4-hydroxyphenylacetic acid, 3-hydroxyphenylacetic acid, vanillic acid, caffeic acid, syringic acid, vanillin, p-coumaric acid, ferulic acid, $m$-coumaric acid, o-coumaric acid, oleuropein, cinnamic acid, luteolin and apigenin. The phenolic standards except two were supplied from Fluka Chemie GmbH (Steinheim, Germany). Hydroxytyrosol and oleuropein were purchased from Extrasynthese (Genay, France). All other chemical reagents are HPLC grade and from Sigma-Aldrich Chemie (Steinheim, Germany).

\subsection{Peroxide value}

Peroxide values (PV) were determined according to the analytical method described in European Official Method of Analysis (Commission Regulation EEC N-2568/91) and expressed as meq $\mathrm{O}_{2} / \mathrm{kg}$. For the evaluation of oxidative stability of oils, samples were subjected to oxidative conditions in dark at $60{ }^{\circ} \mathrm{C}$ and oxidation of oil samples was monitored for eleven days in terms of PV. In the text, the number beside 'PV' term represents the day when the observation was taken during the oxidation test. The $\triangle \mathrm{PV}$ term indicates the difference between PVs at the first day and at the last day of oxidation period. For the replicated samples, the relative standard deviation (RSD) was found in a range $3 \%$ and $11 \%$.

\subsection{Total phenol content}

The total phenol content (TPC) of the olive oil extracts were determined by the Folin-Ciocalteau spectrophotometric method at $765 \mathrm{~nm}$, in terms of gallic acid (mg GA / kg oil) (Montedoro, Servili, Baldioli, \& Miniati, 1992). The measurements were repeated three times. For the replicated samples, relative standard deviation (RSD) was found in a range $0.01 \%$ and $12 \%$.

\subsection{Colour}

A colorimeter (chromometer type CR-400, Minolta Sensing, Osaka, Japan) was used to assess the oil colour. Colour coordinates were measured following the white calibration (for illuminants $D_{65}, Y=93.5, x=0.3140, y=0.3318$ ). $20 \mathrm{ml}$ of olive oil sample was placed into the glass cell and the colour of each sample, in terms of $L^{*}, a^{*}$, and $b^{*}$, was measured at three different positions. The oil colour was reported as the average of three readings.

\subsection{HPLC analysis of phenolic compounds}

\subsubsection{Phenolic extraction}

The phenolic extracts were obtained following the procedure of Brenes, Garcia, Garcia, Rios, and Garrido (1999). Briefly, a sample of olive oil $(14 \mathrm{~g})$ was extracted by using $4 \times 14 \mathrm{ml}$ of methanol/ water $(80: 20 \mathrm{v} / \mathrm{v})$. Methanol was removed, and then $15 \mathrm{ml}$ of acetonitrile was added to the residue and washed with $(3 \times 20 \mathrm{ml})$ of hexane. The resulting acetonitrile solution was evaporated under vacuum and the residue was flushed with nitrogen and dissolved in $1 \mathrm{ml}$ of methanol/water. Final extract was filtered through a $0.45 \mu \mathrm{m}$ pore-size membrane filter (Minisart, Sartorious, Goettingen, Germany) and transferred into a tube. The extract was immediately injected to HPLC as $20 \mu$ l. Gallic acid was used as the internal standard.

\subsubsection{HPLC analysis}

HPLC system with a Perkin Elmer (PE) series 200 pump (Norwalk CT 06859, USA), PE series 200 diode array detector, PE-Nelson 900 series interface, Meta Therm HPLC column heater (series no:9540, Torrance) and a $5 \mu \mathrm{m}, 25 \mathrm{~cm} \times 4.6 \mathrm{~mm}, \mathrm{C} 18$ column (Ace, Aberdeen, Scotland) was used to analyse phenolic compounds. Separation was achieved by elution gradient using an initial composition of $90 \%$ water ( $\mathrm{pH}$ adjusted to 3.1 with $0.2 \%$ acetic acid) and $10 \%$ methanol. The concentration of the methanol 
Table 1

Chemical parameters (PV; meq $\mathrm{O}_{2} / \mathrm{kg}$, TPC; $\mathrm{mg} \mathrm{GA} / \mathrm{kg}$ of oil, colour) and individual phenolic compounds (mg/kg) of extra VOOs of 2005 and 2006 harvest years

\begin{tabular}{|c|c|c|c|c|c|c|c|c|}
\hline Chemical parameters & M & $\mathrm{E}$ & G & A & $\mathrm{D}$ & $\mathrm{N}$ & GE & $\mathrm{AE}$ \\
\hline \multicolumn{9}{|l|}{2005} \\
\hline $\mathrm{Hyt}^{\mathrm{A}}$ & $2.32 \pm 2.36$ & $0.98 \pm 0.4$ & $3.02 \pm 1.96$ & $1.1 \pm 0.4$ & $4.25 \pm 6.01$ & $0.07 \pm 0.09$ & $1.03 \pm 1.3$ & $0.26 \pm 0.03$ \\
\hline $\mathrm{Hdba}^{\mathrm{B}}$ & nd & nd & $0.18 \pm 0.25$ & $0.02 \pm 0.03$ & nd & nd & nd & $0.03 \pm 0.02$ \\
\hline $\operatorname{Tyr}^{\mathrm{C}}$ & $14.17 \pm 19.8$ & $4.3 \pm 3.21$ & $9.42 \pm 6.84$ & $0.67 \pm 0.23$ & $10.51 \pm 5.98$ & $0.25 \pm 0.05$ & $4.02 \pm 4.25$ & $0.45 \pm 0.21$ \\
\hline $\mathrm{Dba}^{\mathrm{D}}$ & nd & nd & $0.11 \pm 0.19$ & nd & nd & nd & nd & nd \\
\hline $\mathrm{Hpha}^{\mathrm{E}}$ & nd & $0.09 \pm 0.15$ & $0.09 \pm 0.07$ & $0.03 \pm 0.05$ & $0.15 \pm 0.21$ & $0.24 \pm 0.02$ & nd & $0.16 \pm 0.07$ \\
\hline $\mathrm{Ca}^{\mathrm{F}}$ & nd & nd & nd & nd & $0.03 \pm 0.04$ & nd & nd & nd \\
\hline $\mathrm{Va}^{\mathrm{G}}$ & $0.07 \pm 0.07^{a}$ & $0.28 \pm 0.08^{\mathrm{ab}}$ & $0.41 \pm 0.24^{\mathrm{ab}}$ & $0.13 \pm 0.03^{\mathrm{a}}$ & $0.47 \pm 0.42^{\mathrm{ab}}$ & $0.03 \pm 0.01^{\mathrm{a}}$ & $0.6 \pm 0.17^{b}$ & $0.43 \pm 0.01^{\mathrm{ab}}$ \\
\hline $\mathrm{Val}^{\mathrm{H}}$ & $0.12 \pm 0.1^{\mathrm{a}}$ & $0.19 \pm 0.02^{\mathrm{a}}$ & $0.13 \pm 0.03^{\mathrm{a}}$ & $0.32 \pm 0.13^{\mathrm{ab}}$ & $0.12 \pm 0.13^{\mathrm{a}}$ & $0.05 \pm 0.07^{\mathrm{a}}$ & $0.29 \pm 0.07^{\mathrm{a}}$ & $0.59 \pm 0.11^{\mathrm{b}}$ \\
\hline Sya ${ }^{I}$ & nd & $0.14 \pm 0.13$ & nd & nd & nd & nd & nd & nd \\
\hline Pcoa $^{J}$ & $0.8 \pm 0.06^{\mathrm{b}}$ & $0.12 \pm 0.05^{a}$ & $0.03 \pm 0.02^{\mathrm{a}}$ & $0.04 \pm 0.04^{\mathrm{a}}$ & $0.06 \pm 0.09^{a}$ & $0.04 \pm 0.01^{\mathrm{a}}$ & $0.01 \pm 0.01^{\mathrm{a}}$ & $0.06 \pm 0.001^{a}$ \\
\hline $\mathrm{Fa}^{\mathrm{K}}$ & $0.27 \pm 0.16$ & nd & nd & nd & $0.05 \pm 0.06$ & nd & nd & $0.02 \pm 0.02$ \\
\hline Peak12 ${ }^{\mathrm{L}}$ & $0.34 \pm 0.3$ & $0.58 \pm 0.54$ & nd & $0.16 \pm 0.28$ & nd & nd & $0.14 \pm 0.13$ & $1.00 \pm 0.03$ \\
\hline Peak13 ${ }^{\mathrm{M}}$ & $0.37 \pm 0.65^{\mathrm{a}}$ & $1.62 \pm 1.4^{\mathrm{ab}}$ & $0.13 \pm 0.12^{\mathrm{a}}$ & $0.05 \pm 0.09^{a}$ & $2.84 \pm 0.22^{\mathrm{b}}$ & nd & $0.11 \pm 0.1^{\mathrm{a}}$ & $0.26 \pm 0.08^{a}$ \\
\hline Peak14 ${ }^{\mathrm{N}}$ & $1.88 \pm 1.8^{\mathrm{ab}}$ & $6.7 \pm 3.04^{\mathrm{b}}$ & nd & $3.33 \pm 0.94^{\mathrm{ab}}$ & $19.52 \pm 1.6^{c}$ & $0.43 \pm 0.61^{\mathrm{a}}$ & nd & $6.36 \pm 0.97^{\mathrm{ab}}$ \\
\hline $\mathrm{Cina}^{\mathrm{O}}$ & $0.53 \pm 0.19^{a}$ & $1.83 \pm 0.61^{\mathrm{b}}$ & $0.36 \pm 0.12^{\mathrm{a}}$ & nd & $0.71 \pm 0.08^{a}$ & $0.04 \pm 0.003^{a}$ & $0.44 \pm 0.12^{\mathrm{a}}$ & $0.02 \pm 0.03^{a}$ \\
\hline Lut $^{\mathrm{P}}$ & $2.4 \pm 0.27^{b}$ & $2.74 \pm 1.24^{\mathrm{b}}$ & $1.38 \pm 0.6^{\mathrm{ab}}$ & $2.27 \pm 0.74^{\mathrm{b}}$ & $0.4 \pm 0.56^{\mathrm{a}}$ & nd & $0.31 \pm 0.39^{a}$ & nd \\
\hline Peak17 ${ }^{Q}$ & $0.87 \pm 0.17$ & $0.70 \pm 0.61$ & $0.32 \pm 0.29$ & nd & nd & nd & $0.18 \pm 0.06$ & nd \\
\hline $\operatorname{Apg}^{\mathrm{R}}$ & $10.66 \pm 1.57^{b}$ & $8.68 \pm 4.58^{b}$ & $4.83 \pm 1.14^{\mathrm{ab}}$ & $0.84 \pm 0.3^{\mathrm{a}}$ & $0.92 \pm 1.3^{\mathrm{a}}$ & $1.46 \pm 1.48^{a}$ & $4.6 \pm 1.14^{\mathrm{ab}}$ & nd \\
\hline PVO & $8.68 \pm 1.58^{\mathrm{b}}$ & $16.08 \pm 3.35^{\mathrm{cd}}$ & $9.93 \pm 0.86^{\mathrm{bc}}$ & $9.40 \pm 1.37^{\mathrm{bc}}$ & $12.28 \pm 0.85^{b c}$ & $22.30 \pm 5.36^{d}$ & $7.37 \pm 1.1^{\mathrm{ab}}$ & $9.98 \pm 3.94^{\mathrm{bc}}$ \\
\hline$\Delta P V$ & $51.95 \pm 9.05$ & $53.42 \pm 14.62$ & $37.73 \pm 2.58$ & $34.14 \pm 4.44$ & $49.6 \pm 14.12$ & $47.56 \pm 0.37$ & $37.58 \pm 12.7$ & $43.1 \pm 22.14$ \\
\hline $\mathrm{L}^{*}$ & $25.59 \pm 0.35^{c}$ & $22.92 \pm 0.70^{\mathrm{a}}$ & $25.21 \pm 0.45^{\mathrm{bc}}$ & $24.61 \pm 0.11^{b}$ & $24.39 \pm 0.62^{b}$ & $24.52 \pm 0.44^{b}$ & $25.40 \pm 0.22^{\mathrm{bc}}$ & $24.94 \pm 0.06^{\mathrm{bc}}$ \\
\hline$a^{*}$ & $-1.97 \pm 0.07^{\mathrm{a}}$ & $-0.07 \pm 0.25^{\mathrm{ef}}$ & $-1.38 \pm 0.38^{\mathrm{ac}}$ & $-1.15 \pm 0.1^{c}$ & $-1.18 \pm 0.42^{\mathrm{bcd}}$ & $-0.48 \pm 0.05^{\mathrm{de}}$ & $-1.80 \pm 0.06^{\mathrm{ab}}$ & $-1.62 \pm 0.04^{\mathrm{ac}}$ \\
\hline$b^{*}$ & $12.95 \pm 0.51^{\mathrm{b}}$ & $10.65 \pm 0.77^{\mathrm{a}}$ & $13.76 \pm 0.46^{\mathrm{b}}$ & $13.22 \pm 0.12^{\mathrm{b}}$ & $12.4 \pm 0.12^{\mathrm{b}}$ & $13.06 \pm 0.09^{\mathrm{b}}$ & $13.67 \pm 0.43^{b}$ & $13.23 \pm 0.12^{\mathrm{b}}$ \\
\hline TPC & $330.92 \pm 35.69^{c}$ & $356.65 \pm 59.2^{c}$ & $274.09 \pm 21.61^{\mathrm{bc}}$ & $329.75 \pm 20.21^{c}$ & $301.99 \pm 83.4^{\mathrm{bc}}$ & $102.4 \pm 32.68^{\mathrm{a}}$ & $245.21 \pm 36.98^{\mathrm{bc}}$ & $186.25 \pm 5.82^{\mathrm{ab}}$ \\
\hline \multicolumn{9}{|l|}{2006} \\
\hline $\mathrm{Hyt}^{\mathrm{A}}$ & $0.25 \pm 0.31$ & $5.78 \pm 5.53$ & $0.07 \pm 0.08$ & $0.21 \pm 0.05$ & $1.97 \pm 3.14$ & $0.43 \pm 0.33$ & $0.24 \pm 0.23$ & $0.23 \pm 0.06$ \\
\hline $\mathrm{Hdba}^{\mathrm{B}}$ & $0.03 \pm 0.06$ & $0.69 \pm 0.93$ & $0.06 \pm 0.07$ & nd & $0.12 \pm 0.19$ & $0.03 \pm 0.04$ & $0.07 \pm 0.12$ & nd \\
\hline Tyr $^{C}$ & $3.31 \pm 0.42^{\mathrm{ab}}$ & $19.3 \pm 16.39^{b}$ & $0.64 \pm 0.07^{a}$ & $0.4 \pm 0.05^{\mathrm{a}}$ & $4.33 \pm 4.73^{\mathrm{ab}}$ & $2.15 \pm 1.02^{\mathrm{ab}}$ & $0.94 \pm 0.64^{\mathrm{a}}$ & $1.11 \pm 0.58^{\mathrm{a}}$ \\
\hline $\mathrm{Dba}^{\mathrm{D}}$ & nd & $0.48 \pm 1.06$ & nd & $0.32 \pm 0.45$ & nd & $0.99 \pm 1.41$ & $0.18 \pm 0.35$ & $0.41 \pm 0.39$ \\
\hline $\mathrm{Hpha}^{\mathrm{E}}$ & nd & $0.04 \pm 0.05$ & $0.03 \pm 0.05$ & nd & $0.04 \pm 0.06$ & $0.1 \pm 0.04$ & $0.08 \pm 0.12$ & nd \\
\hline $\mathrm{Ca}^{\mathrm{F}}$ & $0.006 \pm 0.01$ & $0.05 \pm 0.04$ & nd & $0.02 \pm 0.03$ & $0.01 \pm 0.01$ & $0.03 \pm 0.03$ & nd & $0.04 \pm 0.07$ \\
\hline $\mathrm{Va}^{\mathrm{G}}$ & $0.12 \pm 0.09^{a}$ & $0.3 \pm 0.15^{\mathrm{ab}}$ & $0.38 \pm 0.19^{\mathrm{ab}}$ & $0.72 \pm 0.27^{b}$ & $0.41 \pm 0.23^{\mathrm{ab}}$ & $0.14 \pm 0.14^{\mathrm{ab}}$ & $0.86 \pm 0.48^{\mathrm{b}}$ & $0.59 \pm 0.25^{\mathrm{ab}}$ \\
\hline $\mathrm{Val}^{\mathrm{H}}$ & nd & nd & nd & nd & nd & $0.02 \pm 0.02$ & nd & nd \\
\hline Sya ${ }^{I}$ & $0.09 \pm 0.04^{\mathrm{a}}$ & $0.07 \pm 0.02^{\mathrm{a}}$ & $0.1 \pm 0.05^{\mathrm{a}}$ & $0.09 \pm 0.04^{\mathrm{a}}$ & $0.09 \pm 0.05^{\mathrm{a}}$ & $0.06 \pm 0.02^{\mathrm{a}}$ & $0.22 \pm 0.14^{a}$ & $0.4 \pm 0.09^{b}$ \\
\hline Pcoa $^{J}$ & $0.96 \pm 0.77^{b}$ & $0.2 \pm 0.06^{\mathrm{a}}$ & $0.08 \pm 0.04^{a}$ & $0.19 \pm 0.01^{\mathrm{ab}}$ & $0.02 \pm 0.01^{\mathrm{a}}$ & $0.05 \pm 0.05^{\mathrm{a}}$ & $0.08 \pm 0.04^{a}$ & $0.48 \pm 0.21^{\mathrm{ab}}$ \\
\hline $\mathrm{Fa}^{\mathrm{K}}$ & $0.28 \pm 0.18^{b}$ & $0.09 \pm 0.05^{\mathrm{a}}$ & $0.02 \pm 0.02^{\mathrm{a}}$ & $0.05 \pm 0.004^{a}$ & nd & nd & $0.03 \pm 0.02^{\mathrm{a}}$ & $0.14 \pm 0.06^{\mathrm{ab}}$ \\
\hline Peak12 ${ }^{\mathrm{L}}$ & $0.09 \pm 0.16^{\mathrm{a}}$ & $0.73 \pm 0.89^{\mathrm{ab}}$ & $0.33 \pm 0.14^{\mathrm{ab}}$ & $0.65 \pm 0.17^{\mathrm{ab}}$ & $0.62 \pm 0.11^{\mathrm{ab}}$ & $0.13 \pm 0.18^{\mathrm{ab}}$ & $0.54 \pm 0.34^{\mathrm{ab}}$ & $1.33 \pm 0.24^{\mathrm{b}}$ \\
\hline Peak13 ${ }^{\mathrm{M}}$ & $0.92 \pm 0.12$ & $0.64 \pm 0.64$ & $0.63 \pm 0.19$ & $1.04 \pm 0.47$ & $1.31 \pm 0.85$ & $0.32 \pm 0.39$ & $0.84 \pm 0.44$ & $0.96 \pm 0.21$ \\
\hline Peak14 ${ }^{\mathrm{N}}$ & $2.5 \pm 0.52^{\mathrm{a}}$ & $3.26 \pm 1.24^{\mathrm{a}}$ & $1.2 \pm 0.4^{\mathrm{a}}$ & $4.04 \pm 3.4^{\mathrm{a}}$ & $14.15 \pm 7.33^{b}$ & $1.23 \pm 1.03^{\mathrm{a}}$ & $1.62 \pm 1.11^{\mathrm{a}}$ & $7.12 \pm 2.53^{\mathrm{ab}}$ \\
\hline $\operatorname{Cina}^{\circ}$ & $0.97 \pm 0.22^{\mathrm{a}}$ & $2.55 \pm 0.93^{b}$ & $0.63 \pm 0.08^{a}$ & $0.06 \pm 0.02^{\mathrm{a}}$ & $0.65 \pm 0.29^{a}$ & $0.38 \pm 0.41^{\mathrm{a}}$ & $0.67 \pm 0.34^{\mathrm{a}}$ & $0.13 \pm 0.04^{a}$ \\
\hline Lut $^{\mathrm{P}}$ & $1.91 \pm 0.4$ & $1.57 \pm 1.19$ & $0.56 \pm 0.35$ & $0.67 \pm 0.94$ & $0.07 \pm 0.06$ & $0.5 \pm 0.35$ & $1.43 \pm 0.91$ & $1.67 \pm 1.71$ \\
\hline Peak17 ${ }^{Q}$ & $0.56 \pm 0.59$ & $1.11 \pm 0.5$ & $0.22 \pm 0.20$ & $1.02 \pm 0.97$ & $0.32 \pm 0.08$ & $0.60 \pm 0.60$ & $0.28 \pm 0.24$ & $0.22 \pm 0.31$ \\
\hline $\mathrm{Apg}^{\mathrm{R}}$ & $11.19 \pm 5.7^{\mathrm{a}}$ & $24.06 \pm 7.48^{\mathrm{b}}$ & $4.98 \pm 2.49^{a}$ & $2.52 \pm 0.11^{\mathrm{a}}$ & $1.78 \pm 0.37^{a}$ & $1.85 \pm 0.51^{\mathrm{a}}$ & $3.56 \pm 2.01^{\mathrm{a}}$ & $1.66 \pm 0.53^{\mathrm{a}}$ \\
\hline PVO & $13.45 \pm 5.22$ & $14.55 \pm 3.54$ & $9.57 \pm 3.15$ & $8.21 \pm 2.27$ & $9.84 \pm 1.52$ & $10.31 \pm 4.39$ & $10.37 \pm 0.38$ & $10.64 \pm 2.44$ \\
\hline$\triangle P V$ & $15.41 \pm 0.982$ & $21.65 \pm 9.456$ & $12.79 \pm 1.101$ & $21.66 \pm 4.427$ & $29.99 \pm 5.097$ & $19.51 \pm 3.236$ & $14.37 \pm 8.91$ & $23.16 \pm 9.04$ \\
\hline $\mathrm{L}^{*}$ & $25.37 \pm 0.65^{\mathrm{ab}}$ & $24.76 \pm 0.42^{\mathrm{a}}$ & $25.32 \pm 0.20^{\mathrm{ab}}$ & $24.66 \pm 0.74^{\mathrm{ab}}$ & $24.67 \pm 0.61^{\mathrm{ab}}$ & $24.81 \pm 0.15^{\mathrm{ab}}$ & $25.52 \pm 0.32^{a b}$ & $25.84 \pm 0.17^{b}$ \\
\hline$a^{*}$ & $-1.93 \pm 0.32$ & $-1.52 \pm 0.17^{b}$ & $-2.00 \pm 0.12^{a}$ & $-1.79 \pm 0.13^{a b}$ & $-1.74 \pm 0.07^{\mathrm{ab}}$ & $-1.41 \pm 0.27^{b}$ & $-2.00 \pm 0.11^{\mathrm{a}}$ & $-2.10 \pm 0.08^{a}$ \\
\hline$b^{*}$ & $12.12 \pm 0.88^{a b}$ & $13.08 \pm 0.45^{b}$ & $12.95 \pm 0.76^{b}$ & $10.14 \pm 0.44^{a}$ & $10.11 \pm 0.3^{a}$ & $13.34 \pm 0.13^{b}$ & $13.07 \pm 0.32^{b}$ & $10.66 \pm 0.93^{a}$ \\
\hline TPC & $137.15 \pm 19.92^{\mathrm{a}}$ & $333.37 \pm 3.89^{\mathrm{b}}$ & $91.57 \pm 49.41^{\mathrm{a}}$ & $67.04 \pm 33.05^{\mathrm{a}}$ & $143.8 \pm 5.44^{a}$ & $112.7 \pm 17.82^{\mathrm{a}}$ & $69.03 \pm 21.09^{a}$ & $75.46 \pm 22.33^{\mathrm{a}}$ \\
\hline
\end{tabular}

Different letters within a row indicate samples that are significantly different $(p<0.05)$.

nd: not detected, RT: retention time (min).

A Hydroxytyrosol.

B 4hydroxybenzoic acid.

C Tyrosol.

D 2,3dihydroxybenzoic acid.

E 4hydroxyphenylacetic acid.

F Caffeic acid.

$G$ Vanillic acid.

H Vanillin.

I Syringic acid.

J $p$-coumaric acid.

K Ferulic acid.

L Peak12 (RT:44).

M Peak13 (RT:47.5).

N Peak14 (RT:49.5).

${ }^{\mathrm{O}}$ Cinnamic acid.

P Luteolin.

Q Peak17 (RT:61.5).

$\mathrm{R}$ Apigenin.

was increased to $30 \%$ in $10 \mathrm{~min}$ and maintained for $20 \mathrm{~min}$. Subsequently, the methanol percentage was raised to $40 \%$ in $10 \mathrm{~min}$, maintained for $5 \mathrm{~min}$, increased to $50 \%$ in $5 \mathrm{~min}$, and main- tained another $5 \mathrm{~min}$. Finally, the methanol percentage was increased to 60,70 , and $100 \%$ in 5 min periods. Initial conditions were reached in $15 \mathrm{~min}$. The flow rate was $1 \mathrm{ml} / \mathrm{min}$. Column 


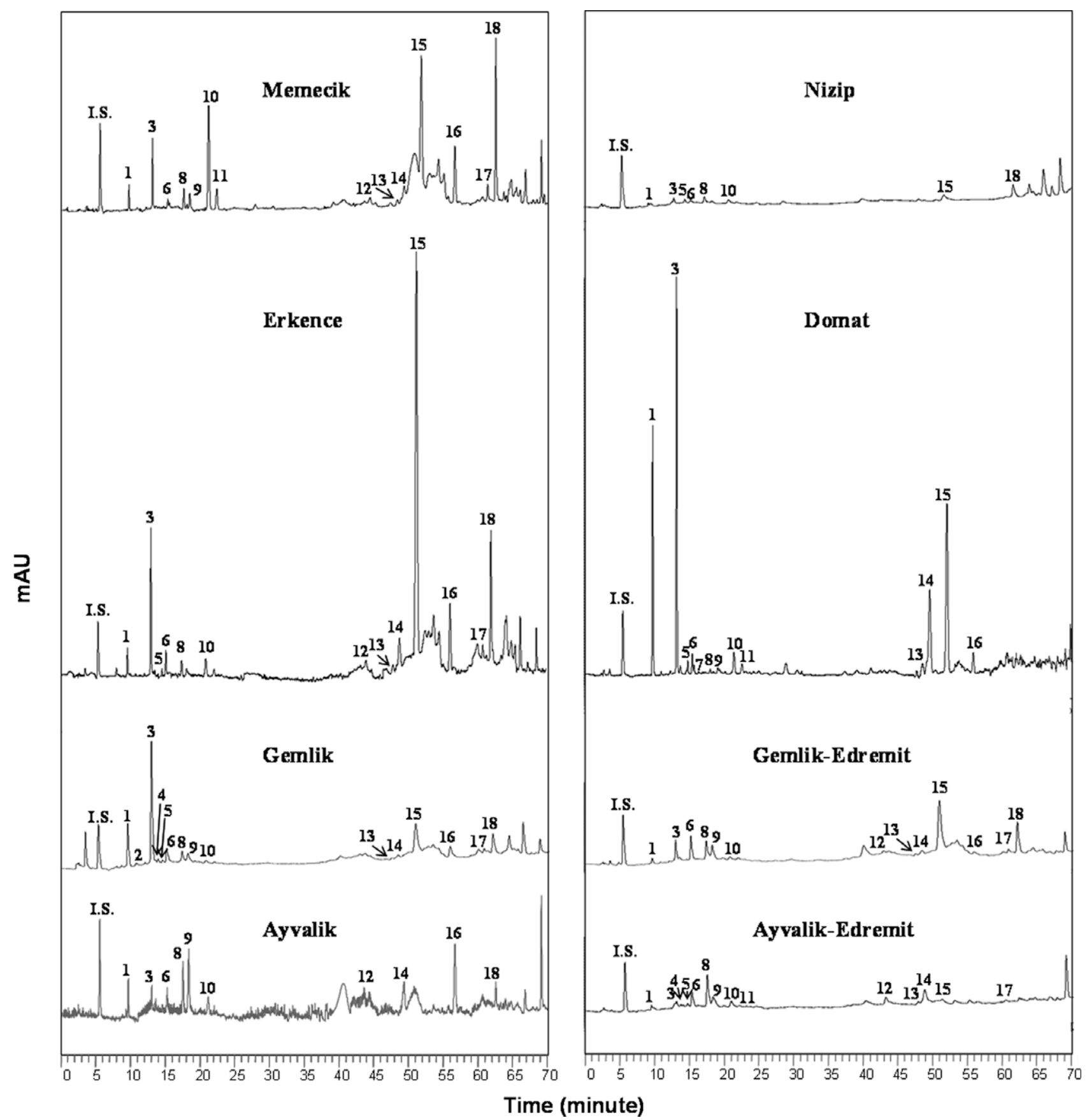

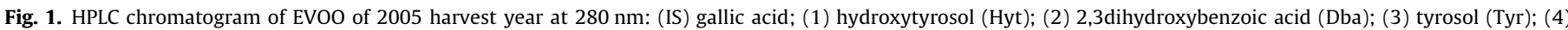

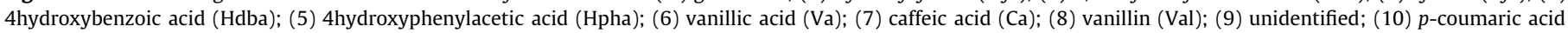

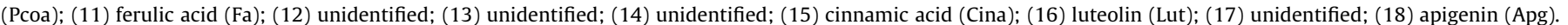

temperature was kept at $35^{\circ} \mathrm{C}$. Chromatograms were obtained at 280 and $320 \mathrm{~nm}$ and different phenolic compounds were identified by comparing their retention times with those of commercial standards. Phenolic compounds were quantified by using their respective 4-point calibration curves.

\subsection{Data analysis}

Chemical data including TPC, PV, and colour measurements were analysed by analysis of variance (ANOVA) using Tukey's test at 5\% significance level in Minitab 14 statistical software (Minitab Inc., State College, USA). Principal component analysis (PCA) and a partial least square-discriminant analysis (PLS-DA) models were built to analyse the influence of the cultivar and harvest year. The multivariate analyses were performed by SIMCA-P v.10.5 (Umetrics, Umea, Sweden). Multivariate data of all measurements obtained over two years were evaluated to investigate the harvest year, effect of cultivar, and growing region. The multivariate data matrix $\mathbf{X}$ of size $(48 \times 28)$ represents 48 samples analysed for two years, with 15 phenolic compounds determined by HPLC, TPC, and 9 PV measurements, and 3 colour parameters. The raw data were transformed into a suitable form for multivariate analysis. Data were autoscaled and, if necessary, variables were normalized prior to the analyses. In Simca-P software the validation of a 
model is done by leave-one-out cross validation and given in statistical $Q^{2}$ measure as the prediction ability of the corresponding model. PLS-DA analyses were performed after a general PCA model of data set.

Multivariate statistical analyses are used in case of more than one variable are collected for samples. Rather than investigating the variable effect on the samples individually, a multivariate data matrix, $\mathbf{X}$, is formed by putting together all variables observed for the samples. $\mathbf{X}$ is subjected to statistical analyses to use the information coming from all measurements at once and extract the most relevant. PCA is a very common, unsupervised multivariate technique and it helps us to interpret in what aspect a sample is different from another. PCA acts on a single data matrix $\mathbf{X}$ of size $(n \times k)$ and reduces a large number of original measurement variables, $k$, to a much smaller number of new, uncorrelated $p$ variables (principal components), which are derived from the correlation matrix of $\mathbf{X}$. Therefore, the original data reduces to a new $(n \times p)$ matrix. Mathematically this can be represented as; $\mathbf{X}=\mathbf{T P}+\mathbf{E}$. The $\mathbf{P}$ matrix is the $(p \times k)$ loadings or principal component matrix, $\mathrm{T}$ is the $(n \times p)$ latent variables or score matrix, $\mathbf{E}$ is the $(n \times k)$ residual matrix. The possible natural groupings within data are visualized by plotting the first two or three latent variables, which are also called score plots. The first principal component includes most explained information (variance); the second principal component carries the next maximum explained information and so on. PLS, as a regression method, connects the information in two blocks of variables $\mathbf{X}$ and $\mathbf{Y}(n \times q)$ by maximizing the correlation between them. PLS-DA is an extension of PLS analysis. In PLS-DA, there is actually no response (quality) matrix $\mathbf{Y}$. A dummy $\mathbf{y}$ variable vector, expressing different values for each class, such as 0 , 1 or 2 is created and processed with $\mathbf{X}$ matrix. The principle of PLS-DA is to find a model that separates classes of observations on the basis of their X-variables. This model is developed from a training set of observations of known class memberships $(\mathbf{y})$. The variable influence on the projection (VIP) of $\mathbf{X}$ into artificial $\mathbf{Y}$ can be demonstrated by the weighted sum of squares of PLS weights, $w$, taking into account the explained Y-variance for a given PLSDA model.

\section{Results and discussions}

The chemical characteristics and identified phenolic components of extra VOOs of two consecutive harvest years are presented in Table 1. This table shows the mean values and standard deviations of analytical parameters and the concentrations of phenolic components for each olive oil sample. According to ANOVA performed on TPC, initial PV and colour parameters, significant differences among the olive oils were detected with the exception of PVs of year 2006 .

\subsection{Peroxide value}

Initial PV (PV0) and the difference between PV0 and PV11 were considered in ANOVA $(\triangle \mathrm{PV})$. PV (meq $\mathrm{O}_{2} / \mathrm{kg}$ ) of all oils from 2005 crop season varied between 7.37 and 22.30. PV of oils produced from erkence and nizip varieties were significantly higher and that of gemlik-edremit olive oil was significantly lower than other varieties. Differences among the extra VOO samples of 2006 crop season were not statistically significant. PVs referring to primary oxidation product of all oil samples were well below the upper legal limit values established by EU regulations (EEC,1991) and Turkish Food Codex (Communication No 98/7) for the EVOO category (PV $<20 \mathrm{meq} / \mathrm{kg}$ oil) except nizip oil of 2005 harvest year. When $\triangle \mathrm{PV}$ was considered, it was observed that gemlik olive oils showed more stable profile against oxidation whereas erkence and domat olive oils were sensitive to oxidation.

\subsection{Total phenol content}

ANOVA analysis showed significant differences among olive oil samples of different varieties (Table 1 ) in two harvest years. Erkence oils had the highest TPC (356.65 $\pm 59.2 \mathrm{mg} \mathrm{GA} / \mathrm{kg}$ oil), while nizip had the lowest $(102.4 \pm 32.68 \mathrm{mg} \mathrm{GA} / \mathrm{kg}$ oil) in 2005 crop season. Lower phenolic content were observed in the second year. Mean TPC of 2006 season varied from $67.04 \pm 33.05$ (ayvalik VOO) to $333.37 \pm 43.89$ (erkence VOO). TPC of the samples could be

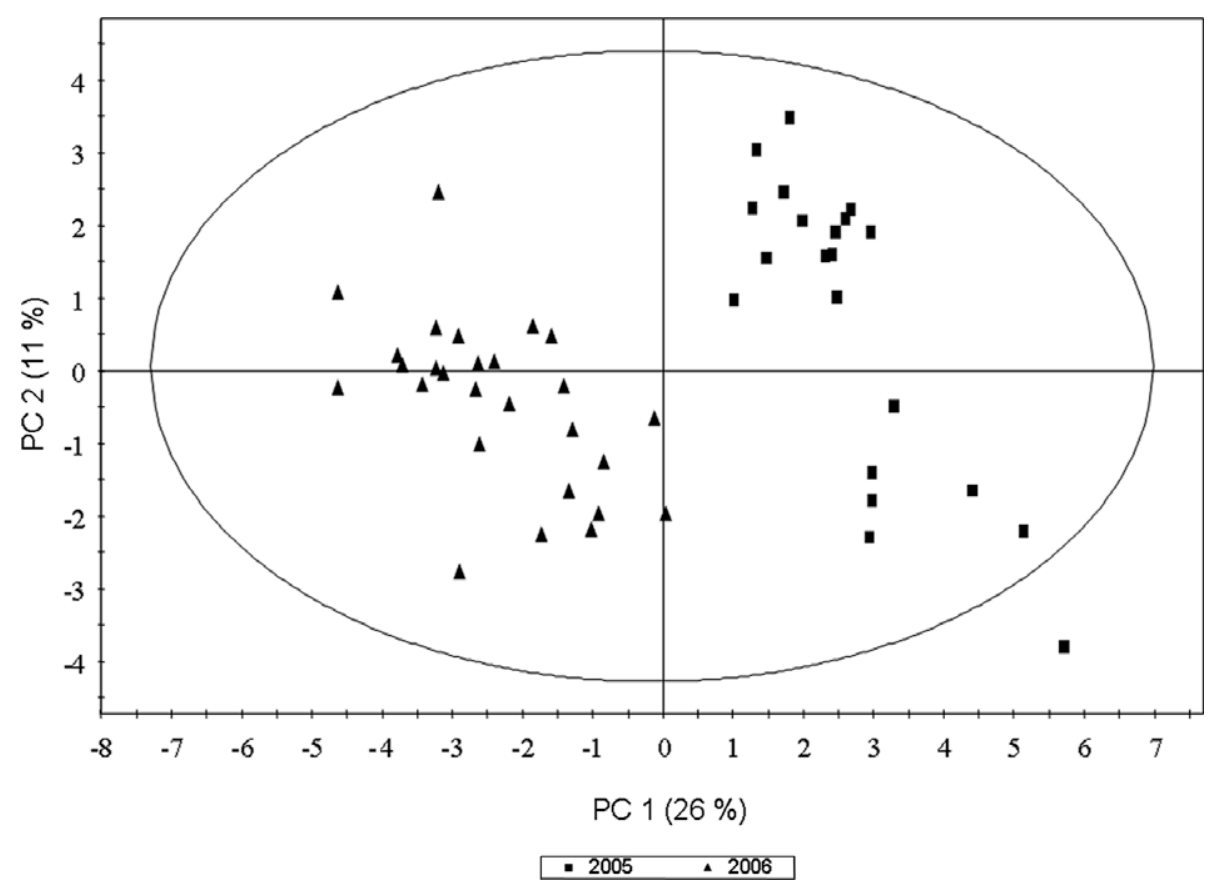

Fig. 2. Score plot of PLS-DA of olive oils of two harvest years. 
considered medium-high levels in accordance with previous reports (Aparicio, Roda, Albi, Gutierrez, 1999; Cerretani et al., 2006; Psomiadou \& Tsimidou, 2002). It was reported that the TPC of Turkish olive oils ranged from 22.5 to $97.1 \mathrm{mg}$ of GA/ kg of oil in 2003 season (Tanilgan, Ozcan, \& Unver, 2007). However, it is difficult to reach a general conclusion about TPC if it is not for the same harvest year.

\subsection{Colour}

Considering CIE- $L^{*} a^{*} b^{*}$ colour coordinates, oil samples were found significantly different for two harvest years. The results showed that erkence and nizip oils had different colour parameters from other oils (Table 1 ). In both years, erkence had the lowest $L^{*}$ and less negative $a^{*}$ values, while memecik, gemlik and ayvalik oils consistently showed higher $L^{*}$ and more negative $a^{*}$. Erkence oils were observed as the darkest of all oils. Nizip oils showed similarities to erkence oils in $a^{*}$.

\subsection{Phenol composition}

Typical HPLC chromatograms of EVOO samples of 2005 harvest year are given in Fig. 1. In all oil samples, the major phenolic com- pounds identified were hydroxytyrosol, tyrosol, vanillic acid, $p$ coumaric acid, vanillin, oleuropein, cinnamic acid, luteolin, and apigenin (Table 1 ). The data were expressed in $\mathrm{mg} / \mathrm{kg}$ olive oil and represented the average of different batches of the same cultivar ( 2 to 5 in each year). Simple phenols such as hydroxytyrosol and tyrosol were present in all olive oils studied. The concentration of tyrosol in oils was greater than that of hydroxytyrosol for two years. A detailed discussion of distribution of phenolic compounds in different olive oils is covered in the following sections. A few points should be stated in this part. The main phenolic acids identified in this study; such as vanillic acid, syringic acid and p-coumaric acid were also determined previously in Turkish olive oils as $\quad 0.33-0.83 \mathrm{mg} / \mathrm{kg}, \quad 0.49-1.46 \mathrm{mg} / \mathrm{kg}$, and $0.5-10.37 \mathrm{mg} / \mathrm{kg}$, respectively (Nergiz \& Unal, 1991). Memecik and erkence oils contain higher levels of luteolin and apigenin for two years. These flavonoid compounds were characterised in most of the Spanish, Italian and Portuguese virgin olive oils (Vinha et al., 2005). Several phenolic compounds, such as 4-hydroxybenzoic, 4-hydroxyphenylacetic, and 2,3-dihydoxybenzoic acids, were present in very low concentrations. Although cinnamic acid was found in trace amounts in all oils for the first year, its concentration increased in the following year. This phenolic acid was identified and quantified in high levels in olive oils previously by Montedoro et al.
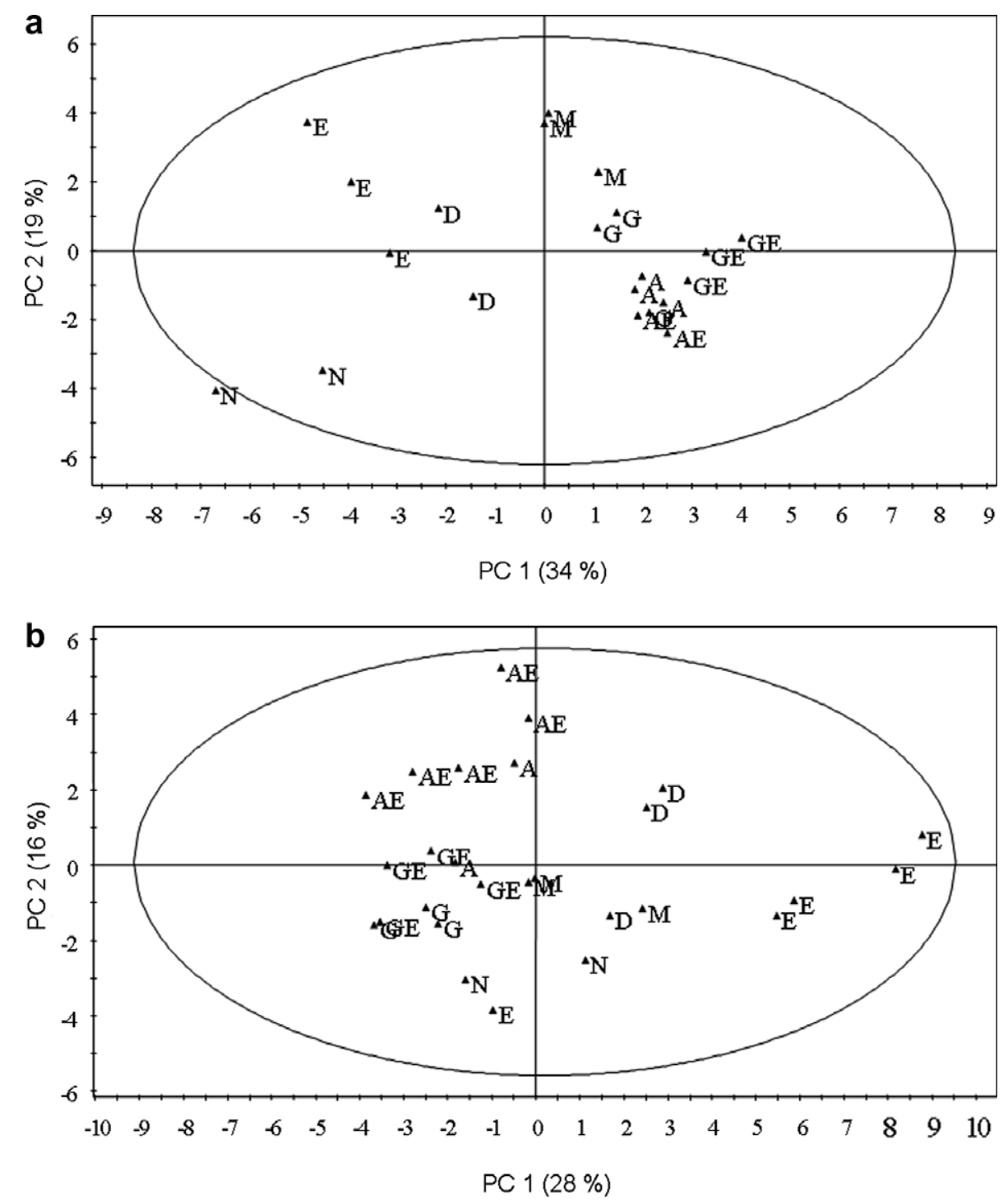

Fig. 3. Score plots of PCA for 2005 (a) and 2006 (b). 
(1992). Among the oil samples, nizip oil had the lowest contents of phenolic compounds for two years. HPLC chromatograms of Turkish EVOO in Fig. 1 were compared with those given in the studies of Brenes and co-workers to identify some of the secoiridoids and lignans qualitatively since the method for phenolic identification was adopted from their studies (Brenes et al., 2000). There are two unidentified peaks (numbers 12 and 13) appeared between 47-50 min. The peak 14 can be considered as oleuropein aglycon. Similarly, the unidentified peak (number 17) between luteolin and apigenin might be identified as ligstroside aglycon. The peak (number 12) at around $44 \mathrm{~min}$ can be attributed to dialdehydic form of elenolic acid linked to tyrosol. From this comparison, lignans (1-acetoxypinoresinol and pinoresinol) may be assumed to be absent in the olive oils studied here. In order to incorporate these four phenols in the data analysis, peaks 13 and 14 were quantified in terms of oleuropein, peaks 12 and 17 were quantified in terms of tyrosol.

The relationship between TPC and oxidative stability has been discussed by others $(r=0.72$ in Blekas, Psomiadou, Tsimidou, \& Boskou, 2002; $r=0.87$ in Aparicio, Roda, Albi, \& Gutierrez, 1999). In this study, a positive relation between $\triangle \mathrm{PV}$ and TPC was observed $(r=0.56)$. High total phenolic concentration does not always mean 'protection against oxidation'. Phenolic compounds might contribute to the oxidative stability individually or through synergic effects. Small contribution of the minor components to the stability of oil was reported by Mateos, Domianguez, Espartero, and Cert (2003). Oxidative stability was found to be correlated to total polyphenols with correlation coefficient $r$ ranging from 0.338 to 0.669 and also to hydroxytyrosol with $r$ of 0.397 in Tura et al. (2007). The dialdehydic form of elenolic acid linked to hydroxytyrosol and to tyrosol, and aglycon derivatives of oleuropein were shown to be positively correlated to the induction period (hours) of olive oil by De Stefano, Piacquadio, Servili, Di Giovacchino, and Sciancalepore (1999). In this study, when individual phenolic compounds and $\triangle \mathrm{PV}$ were compared, weak correlations were found with vanillin, syringic acid, and colour parameter $a^{*}$, as 0.55 , $-0.42,0.51$, respectively, in terms of correlation coefficient $r$.

\subsection{Influence of harvest year}

According to the PCA model of data X, the samples of different years formed groups. Then, a two-component PLS-DA model with $R_{x}^{2}=0.37, R_{y}^{2}=0.9, Q^{2}=0.84\left(R^{2}\right.$ of cross-validation predictions) was built to further resolve the effect of the harvest year by using
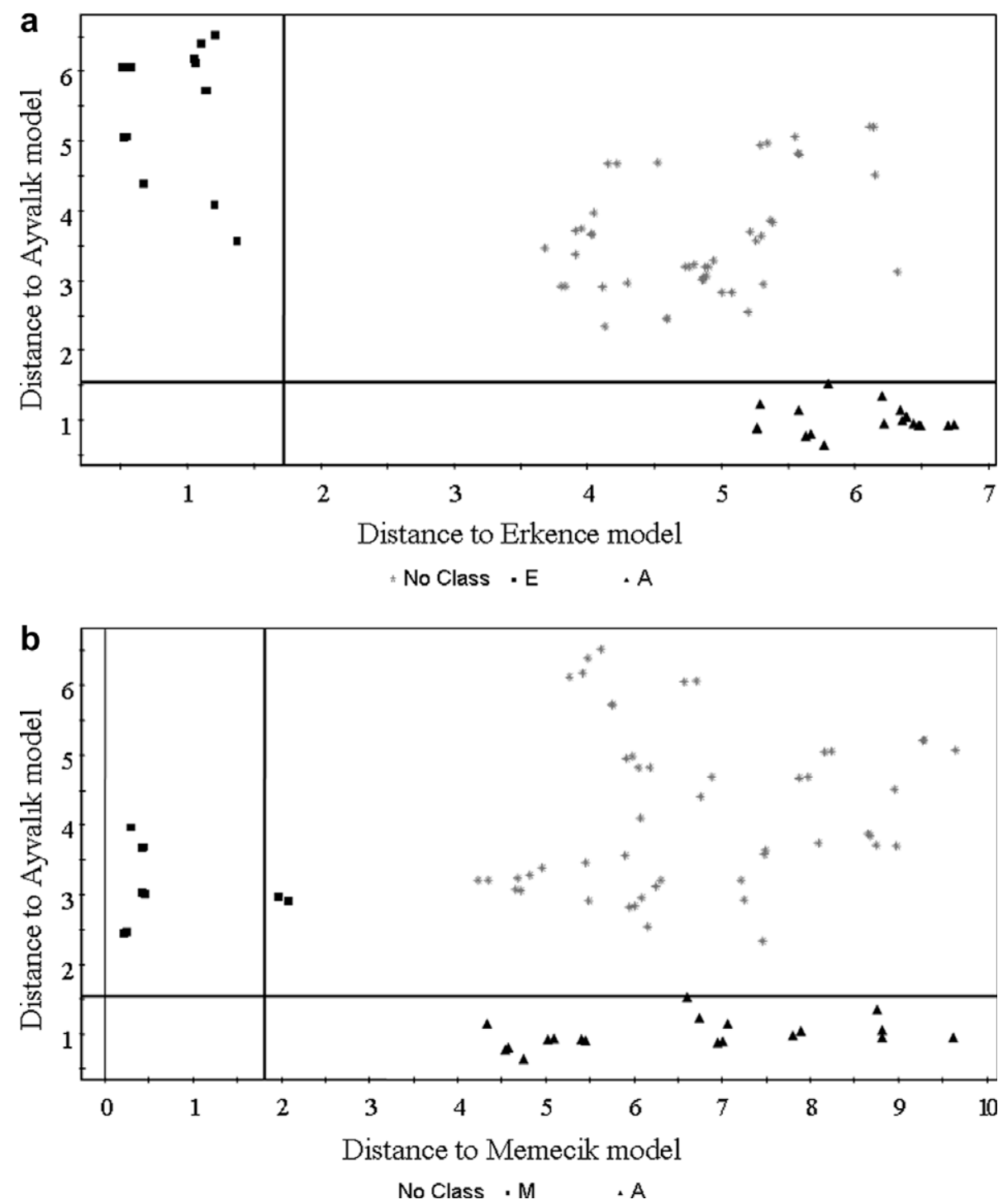

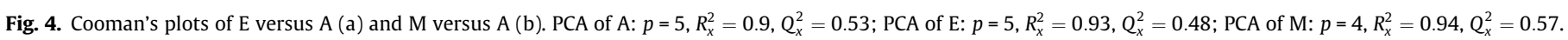


all observations over two years. Biplot of PLS-DA model shows that harvest year is a strong discriminating component (Fig. 2). The samples of 2006 year were clustered together in the same area of the plot and separated from the samples of 2005 year. The sample on the outside of the control ellipse is the nizip oil of 2005 year. The model VIP values show that the most influential variables in the group separation in descending order are vanillin (1.97), syringic (1.92), PV11 (1.67), and $a^{*}$ (1.19). Other variables are TPC and caffeic acid. The reason of high discriminating power of vanillin and syringic acid is the absence or trace presence of these phenols in one particular year and the presence of them in higher concentrations in other harvest year. Different phenolic compositions with respect to harvest year have been also reported by other authors. Romero, Tovar, Ramo, and Motilva (2003) investigated the composition of VOOs produced over four consecutive crop seasons in the region of the protected designation of origin "Les Garrigues" (Catalonia, Spain), taking the harvest period and the climatic conditions into consideration and found that phenolic profiles were influenced mainly by the cumulative rainfall. Effect of crop season on the composition of olive oils with special emphasis on the phenolic fraction was also studied by Morello, Romero, and Motilva (2006) and indicated that the main differences between crop seasons were observed in secoiridoid derivatives, vanillin, tyrosol, apigenin, luteolin, and lignans.

\subsection{Influence of olive variety}

The effect of the cultivar on the phenolic compositions of extra VOOs was investigated by PCA. A two-component PCA model with $R^{2}=0.52, Q^{2}=0.26$ was built for 2005 harvest year (Fig. 3a). Erkence, domat and nizip oils separated from all the other samples while gemlik and ayvalik oils cluster closely on the other half of the control ellipse. Memecik oils lay between these groupings, but more closely to gemlik and ayvalik oils. A three-component PCA model with $R^{2}=0.57, Q^{2}=0.17$ was built for 2006 oils (Fig. 3b). A similar pattern to 2005 year was observed in groups. Erkence,
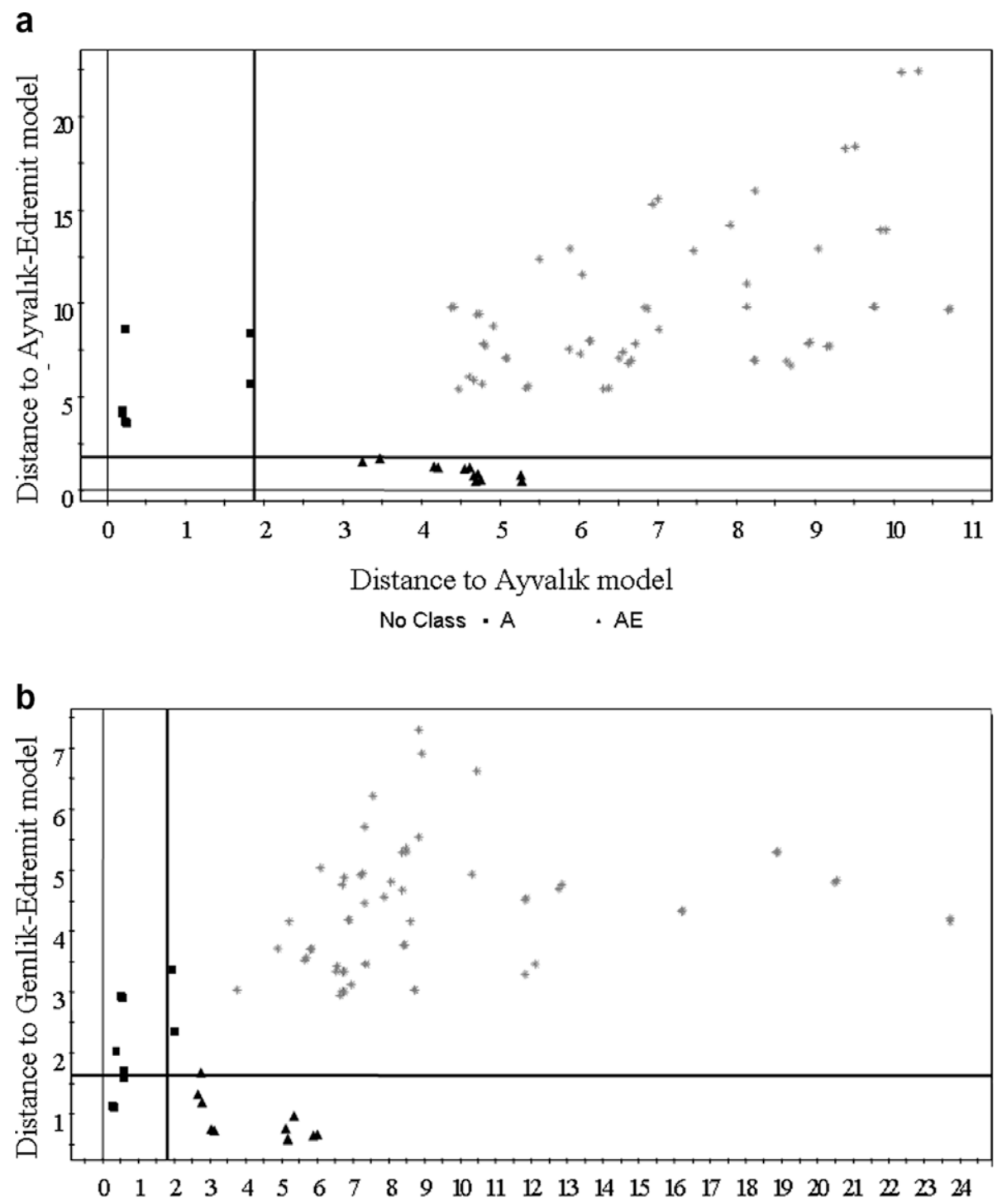

\section{Distance to Gemlik model \\ No Class - G $\quad \cdot$ GE}

Fig. 5. Cooman's plot of A versus AE (a) and G versus GE (b).PCA of A: $p=3, R_{x}^{2}=0.97, Q_{x}^{2}=0.90$; PCA of AE: $p=5, R_{x}^{2}=0.96, Q_{x}^{2}=0.73$; PCA of G: $p=4, R_{x}^{2}=0.97, Q_{x}^{2}=0.78$; PCA of GE: $p=3, R_{x}^{2}=0.9, Q_{x}^{2}=0.67$. 
domat and nizip oils grouped separately from gemlik and ayvalik oils. Memecik oils again appeared in the middle of the plot. The following consistent patterns that led to certain clusters in both years were observed: 1 . Memecik oils separate from others by high content of $p$-coumaric acid and apigenin. 2. Erkence oils have high cinnamic acid, apigenin and TPC both years. 3. Domat oils are high in aglycon of oleuropein. Memecik, erkence, ayvalik and ayvalik-edremit oils have moderate amount of this secoiridoid derivative compared to domat oils, whereas gemlik and nizip oils have practically none. 4. Generally, ayvalik and gemlik oils (from Bornova and Edremit groves) have high vanillic acid and vanillin. 5. All ayvalik oils have very poor cinnamic acid content unlike erkence oils. 6. Hydroxy-phenilaceticacid determined in both years contributes the separation of Nizip oils.

The classification method, Soft Independent Modelling Class Analogy (SIMCA), was used to determine the class membership of the oil samples and to form the known classes of variety. SIMCA develops principal component models for each training class separately and provides information including critical distances which can be calculated as the geometric distance of each object from the principal component models. Following the modelling for classes, each sample is fitted to each model and classification of the sample with corresponding class is achieved. SIMCA results can be visualized by Cooman's plot, which shows the discrimination of two classes. In Cooman's plot, the distance from the model for class 1 is plotted against that from model 2 and both axes indicate the critical distances. Four zones are defined on the plot: class 1, class 2 (the object is situated within the boundaries of only one class), overlap of classes 1 and 2 (the object is situated inside the boundaries of more than one class), and outlier zone (far from both classes). By plotting objects in this plot it is easy to visualize how certain a classification is (Berrueta, Alonso-Salces, \& Heberger, 2007). In order to show the separation of olive oils of different cultivars, ayvalik versus memecik oils and ayvalik versus erkence oils were plotted and shown in Fig. 4a and 4b. Ayvalik is one of the most common olive varieties in the north side of the west (Aegean) cost of Turkey, while memecik is the dominant cultivar in the south side of the west cost. Erkence variety is cultivated only in a very narrow area (Karaburun, Cesme and Urla regions of city of Izmir). Phenolic content of erkence oil was found consistently and significantly higher than the other virgin olive oils over two harvest years studied, besides its high oil productivity. SIMCA models were created for ayvalik, memecik and erkence oils of two seasons and model parameters are given in Fig. 4. According to the Coomans'plots of the models, these olive oil types have different phenolic and chemical compositions that could lead to differentiation (Fig. 4a and b). Samples did not exceed their limits and were correctly classified into their classes. Separation of ayvalik oils from other varieties was also investigated and it was observed that ayvalik oils differ from all varieties according to Cooman's plots.

Vinha et al. (2005) demonstrated that differentiation between olive oil samples with the same geographical origin and different variety was possible. In another study, the phenolic composition was found to be not useful in discriminating the olive oil samples due to the fact that the phenolic content of oils was affected not only by the olive cultivars, but also climatic and environmental conditions, agronomic practice and the technological process (Cerretani et al., 2006). In our work, olive fruits were harvested about at the same time in two consecutive years from the same nurseries, where the trees were subjected to the similar agronomic procedures. Olive oils were extracted by the same process. In order to average out the climatic conditions, it would obviously be more informative to monitor the oils over more than three years. On the other hand, even the two-year study in our case provided an information depicting discrimination among olive oils of different cultivars.

\subsection{Geographical origin}

The effect of geographical origin was investigated by the differences in the oils of ayvalik and gemlik varieties harvested in two different regions. The ayvalik and gemlik oils from different growing regions could be differentiated based on their phenolic profiles with PCA class models. Model parameters and Cooman's plots for two oils are shown in Fig. 5. Ayvalik oils from Izmir region were separated from those of Edremit area, while no clear separation was observed between gemlik and gemlik-edremit oils.

\section{Conclusions}

This study can be considered as a preliminary characterisation of Turkish olive oils in terms of phenolic compounds since the demand for authenticated food products and also olive oil has been increasing. Major phenolic compounds in Turkish extra virgin olive oils from six important olive cultivars are hydroxytyrosol, tyrosol, vanillic acid, $p$-coumaric acid, cinnamic acid, luteolin, and apigenin. The harvest year was found to be the most effective factor that discriminates the olive oil samples regardless of their botanical origin. The discrimination among olive oil samples were shown by their SIMCA models with respect to the cultivar and it was observed that the oils of different olive species have sufficiently different phenolic compound distributions that put them in separate classes. The oxidative stability in terms of PV over an extended period at an elevated temperature was found weakly related to vanillin, syringic acid, and colorimetric ordinate $a^{*}$.

\section{Acknowledgements}

This project was supported by TUBITAK; the Scientific and Technical Research Council of Turkey (project ID: TUBITAK-TOVAG-1040333).

\section{References}

Alves, M. R., Cunha, S. C., Amaral, J. S., Pereira, J. A., \& Oliveira, M. B. (2005). Classification of PDO olive oils on the basis of their sterol composition by multivariate analysis. Analytica Chimica Acta, 549, 166-178.

Aparicio, R., Roda, L., Albi, M. A., \& Gutierrez, F. (1999). Effect of various compounds on virgin olive oil stability measured by rancimat. Journal of Agricultural and Food Chemistry, 47, 4150-4155.

Bendini, A., Cerretani, L., Carrasco-Pancorbo, A., Gomez-Caravaca, A. M., SeguraCarretero, A., Fernandez-Gutierrez, A., et al. (2007). Phenolic molecules in virgin olive oils: A survey of their sensory properties, health effects, antioxidant activity and analytical methods. An overview of the last decade. Molecules, 12, 1679-1719.

Berrueta, L. A., Alonso-Salces, R. M., \& Heberger, K. (2007). Supervised pattern recognition in food analysis. Journal of Chromatography A, 1158, 196-214.

Blekas, G., Psomiadou, E., Tsimidou, M., \& Boskou, D. (2002). On the importance of total polar phenols to monitor the stability of Greek virgin olive oil. European Journal of Lipid Science and Technology, 104, 340-346.

Brenes, M., Garcia, A., Garcia, P., Rios, J. J., \& Garrido, A. (1999). Phenolic compounds in Spanish olive oils. Journal of Agricultural and Food Chemistry, 47, 3535-3540.

Brenes, M., Hidalgo, F. J., Garcia, A., Rios, J. J., Garcia, P., Zamora, R., et al. (2000). Pinoresinol and 1-Acetoxypinoresinol, two new phenolic compounds identified in olive oil. Journal of American Oil Chemists' Society, 77, 715-720.

Cerretani, L., Bendini, A., Del Caro, A., Piga, A., Vacca, V., Caboni, M. F., et al. (2006). Preliminary characterisation of virgin olive oils obtained from different cultivars in Sardinia. European Food Research Technology, 222, 354-361.

De Stefano, G., Piacquadio, P., Servili, M., Di Giovacchino, L., \& Sciancalepore, V. (1999). Effect of extraction systems on the phenolic composition of virgin olive oils. Lipid-Fett, 101, 328-332.

Gomez-Alonso, S., Salvador, M. D., \& Fregapane, G. (2002). Phenolic compounds profile of Cornicabra virgin olive oil. Journal of Agricultural and Food Chemistry, 50, 6812-6817.

Haddada, F. M., Mania, H., Daoud, D., Fernandez, X., Lizzani-Cuvelier, L., \& Zarrouk, M. (2007). Profiles of volatile compounds from some monovarietal Tunisian virgin olive oils. Comparison with French PDO. Food Chemistry, 103, 467-476.

International Olive Council, <http://www.internationaloliveoil.org>. Accessed 14.03.08.

Kalua, C. M., Allen, M. S., Bedgood, D. R., Bishop, A. G., \& Prenzler, P. D. (2005). Discrimination of olive oils and fruits into cultivars and maturity stages based 
410

D. Ocakoglu et al./Food Chemistry 113 (2009) 401-410

on phenolic and volatile compounds. Journal of Agricultural and Food Chemistry, 53, 8054-8062.

Kiritsakis, A. K. (1998). Flavour components of olive oil-A review. Journal of the American Oil Chemists Society, 75(6), 673-681.

Mateos, R., Dominguez, M. M., Espartero, J. L., \& Cert, A. (2003). Antioxidant effect of phenolic compounds, r-tocopherol, and other minor components in virgin olive oil. Journal of Agricultural and Food Chemistry, 51, 7170-7175.

Medina, E., Brents, M., Romero, C., Garcia, A., \& De Castro, A. (2007). Main antimicrobial compounds in table olives. Journal of Agricultural and Food Chemistry, 55, 9817-9823.

Montedoro, G., Servili, M., Baldioli, M., \& Miniati, E. (1992). Simple and hydrolysable phenolic compounds in virgin olive oil. 1 . Their extraction, separation, and quantitative and semiquantitative evaluation by HPLC. Journal of Agricultural and Food Chemistry, 40, 1571-1576.

Morello, J. R., Romero, M. P., \& Motilva, M. J. (2006). Influence of seasonal conditions on the composition and quality parameters of monovarietal virgin olive oils. Journal of the American Oil Chemists Society, 83, 683-690.

Nergiz, C., \& Unal, K. (1991). Determination of phenolic acids in virgin olive oil. Food Chemistry, 39, 237-240.

Psomiadou, E., \& Tsimidou, M. (2002). Stability of virgin olive oil. 1. Autoxidation studies. Journal of Agricultural and Food Chemistry, 50, 716-721.

Ranalli, A., Contents, S., Schiavone, C., \& Simone, N. (2001). Malaxing temperature affects volatile and phenol composition as well as other analytical features of virgin olive oil. European Journal of Lipid Science and Technology, 103, 228-238.

Romero, M. P., Tovar, M. J., Ramo, T., \& Motilva, M. J. (2003). Effect of crop season on the composition of virgin olive oil with protected designation of origin "Les Garrigues". Journal of the American Oil Chemists Society, 80, 423-430.
Servili, M., Selvaggini, R., Esposto, S., Taticchi, A., Montedoro, G., \& Morozzi, G. (2004). Health and sensory properties of virgin olive oil hydrophilic phenols: Agronomic and technological aspects of production that affect their occurrence in the oil. Journal of Chromatography A, 1054, 113-127.

Stefanoudaki, E., Kotsifaki, F., \& Koutsaftakis, A. (1997). The potential of HPLC triglyceride profiles fort he classification of Cretan olive oils. Food Chemistry, $60(3), 425-432$.

Tanilgan, K., Ozcan, M. M., \& Unver, A. (2007). Physical and chemical characteristics of five Turkish olive (Ilea europe $L$ ) varieties and their oils. Grass Y Aceites, 58(2), 142-147.

Tovar, M. J., Motilva, M. J., \& Romero, M. P. (2001). Changes in the phenolic composition of virgin olive oil from young trees (Ole europaea L cv. Arbequina) grown under linear irrigation strategies. Journal of Agricultural and Food Chemistry, 49, 5502-5508.

Tuck, K. L., Hayball, P. J., \& Stupans, I. (2002). Structural characterisation of the metabolites of hydroxytyrosol, the principal phenolic component in olive oil, in rats. Journal of Agricultural and Food Chemistry, 50, 2404-2409.

Tura, D., Gigliotti, C., Pedo, S., Fila, O., Bassi, D., \& Serraiocco, A. (2007). Influence of cultivar and site of cultivation on levels of lipophilic and hydrophilic antioxidants in virgin olive oils (Plea European $L$ ) and correlations with oxidative stability. Sciential Horticulture, 112, 108-119.

Vinha, A. F., Ferreres, F., Silva, B. M., Valentao, P., Gonçalves, A., Pereira, J. A., et al. (2005). Phenolic profiles of Portuguese olive fruits (Ole europaea $L$ ): Influences of cultivar and geographical origin. Food Chemistry, 89, 561-568.

Visioli, F., Poi, A., \& Cali, C. (2002). Antioxidant and other biological activities of phenols from olives and olive oil. Medicinal Research Reviews, 22(1), 65-75. 